\title{
Hysteroscopic insemination of small numbers of spermatozoa at the uterotubal junction of preovulatory mares
}

\author{
L. H. A. Morris ${ }^{1}$, R. H. F. Hunter ${ }^{2}$ and W. R. Allen ${ }^{1}$ \\ ${ }^{1}$ University of Cambridge, Department of Clinical Veterinary Medicine Equine Fertility Unit, Mertoun Paddocks, \\ Woodditton Road, Newmarket, Suffolk CB8 9BH, UK; and ' Department of Clinical Studies - Reproduction, Royal Veterinary University, \\ Copenhagen, Denmark
}

\begin{abstract}
Mares were inseminated with motile spermatozoa suspended in 30-150 $\mu$ l Tyrode's medium directly onto the uterotubal papilla at the anterior tip of the uterine horn, ipsilateral to the ovary containing a dominant preovulatory follicle of $\geq 35 \mathrm{~mm}$ in diameter, by means of a fine gamete intrafallopian transfer (GIFT) catheter passed through the working channel of a strobed light videoendoscope. Insemination of 10, 8 , $25,14,11$ and 10 mares with, respectively, 10.0, 5.0, 1.0, $0.5,0.1$ or $0.001 \times 10^{6}$ motile spermatozoa resulted in conception rates of, respectively, 60, 75, 64, 29, 22 and $10 \%$. Deposition of $1.0 \times 10^{6}$ motile spermatozoa onto the uterotubal papilla began to approach the limit of successful fertilization. These doses are far lower than the $3-15 \times 10^{9}$ spermatozoa normally ejaculated by fertile stallions during mating, and the accepted minimum dose of $500 \times 10^{6}$ spermatozoa used for conventional uterine body insemination in mares. The simplicity of the technique offers a practical means of exploiting new breeding technologies that require very small numbers of spermatozoa in horse breeding.
\end{abstract}

\section{Introduction}

In vitro experiments have examined the binding of stallion spermatozoa to cultured endosalpingeal cells (Thomas et al., 1994a,b; Lefebvre et al., 1995), the response of stallion spermatozoa to treatment with calcium ionophore (Zhang et al., 1991) and the putative chemotactic influence of equine follicular fluid on stallion spermatozoa (Navarro et al., 1998). However, studies of the transport and storage of spermatozoa in the female reproductive tract are most meaningful when performed in vivo. Scott et al. (in press) used scanning electron microscopy on samples of Fallopian tube and endometrium recovered post mortem from mares at a fixed time after a single mating to demonstrate that considerable numbers of spermatozoa are located in crypts in the wall of the papilla on the uterine side of the uterotubal junction.

The studies of Day (1942), Mann et al. (1956) and Pickett and Voss (1975) established the concept that to achieve maximum fertility in mares, a single insemination dose of fresh or cooled extended semen should contain a minimum of $500 \times 10^{6}$ spermatozoa showing progressive motility of $>70 \%$. However, to exploit the availability of new reproductive technologies, such as sex selection of spermatozoa by fluorescence-activated cell sorting (FACS), a method of insemination is required that uses very small numbers of spermatozoa. This is emphasized by the

Received 3 March 1999. achievement of maximum sorting rates during FACS analysis of only $2-5 \times 10^{6}$ selected motile spermatozoa $\mathrm{h}^{-1}$ (Johnson et al., 1998). This limitation would preclude its use in horse breeding if it were to be combined with conventional high-dose artificial insemination requiring $500 \times 10^{6}$ spermatozoa. Limited success has been demonstrated using a hysteroscopic insemination procedure to deposit as few as $1 \times 10^{6}$ spermatozoa at the uterotubal junction (Manning et al., 1998; Vazquez et al., 1998).

In the light of the findings of Scott et al. (in press) of putative preovulatory sperm storage on the uterine side of the uterotubal papilla, and the ready access to this 'oviductal gateway' in mares by trans-cervical videoendoscopic hysteroscopy (Bracher and Allen, 1992), the aim of the present study was to examine the potential to achieve high fertility in oestrous mares by a single hysteroscopic deposition of small numbers of spermatozoa onto the uterotubal papilla, ipsilateral to the ovary containing a preovulatory follicle. Sequential reduction of the numbers of spermatozoa in the inseminate would enable the minimum effective dose of spermatozoa to be determined for successful hysteroscopic insemination.

\section{Materials and Methods}

\section{Synchronization of oestrus}

At the end of the 1998 breeding season, pony and Thoroughbred experimental mares were inseminated during 
oestrus which was induced by an i.m. injection of 250-375 $\mu \mathrm{g}$ of the $\mathrm{PGF}_{2 \alpha}$ analogue cloprostenol (Estrumate; ScheringPlough Animal Health, Uxbridge). At the start of the 1999 breeding season, oestrus was induced and synchronized by oral administration of the synthetic progestagen altrenogest (Regumate; Hoechst Roussel Vet, Milton Keynes) for 10 days $\left(0.044 \mathrm{mg} \mathrm{kg}^{-1}\right)$ followed by an i.m. injection of cloprostenol on day 10, and insemination was conducted during the subsequent oestrus.

\section{Preparation of the inseminate}

Semen was collected by artificial vagina, from either of two identical twin pony stallions of proven high fertility, within $4 \mathrm{~h}$ before the insemination of each mare. Sperm motility was assessed microscopically and the ejaculate was diluted at a ratio of 2:1 (v/v) with the skim milk-based semen extender described by Kenney et al. (1975). The diluted semen was then allowed to cool slowly to room temperature $\left(20-25^{\circ} \mathrm{C}\right)$ for $1 \mathrm{~h}$ before a $1.5 \mathrm{ml}$ aliquot was carefully layered onto $2 \mathrm{ml}$ of a 90:45\% Percoll (Sigma Chemical Co., St Louis, $\mathrm{MO})$ discontinuous density gradient in a $15 \mathrm{ml}$ conical centrifuge tube. The $90 \%$ Percoll was diluted with HEPESbuffered Tyrode's medium (Grøndahl et al., 1996) to make a $45 \%$ solution. The sperm suspension was centrifuged through the Percoll layers for $5 \mathrm{~min}$ at $200 \mathrm{~g}$ and subsequently for $10 \mathrm{~min}$ at $800 \mathrm{~g}$, and the supernatant was discarded to leave a $100 \mu \mathrm{l}$ pellet of highly concentrated spermatozoa. The pellet was resuspended in $900 \mu \mathrm{l}$ HEPESbuffered Tyrode's medium. Sperm concentration was determined by a stallion sperm counter (Densimeter Model 534A; Animal Reproduction Systems, Chino) and total progressive motility was reassessed subjectively by a single experienced operator to provide insemination doses of 10.0, $5.0,1.0,0.5,0.1$ or $0.001 \times 10^{6}$ motile spermatozoa. The time required to process each ejaculate in this manner was 45-60 min.

\section{Uterotubal insemination}

The predetermined insemination dose of motile spermatozoa, suspended in 30-150 $\mu$ l Tyrode's medium, was aspirated into an equine GIFT catheter (Cook Veterinary Products, Brisbane) using a $2.5 \mathrm{ml}$ disposable syringe attached to the injection port on the distal end of the catheter. The loaded catheter was withdrawn into an outer polypropylene cannula which was passed down the working channel of a Pentax EPM 3000 videoendoscope (Pentax UK Ltd, Slough). The flexible endoscope $(1.6 \mathrm{~m}$ in length with an outer diameter of $12 \mathrm{~mm}$ ) was guided through the cervix and propelled forward through the uterine lumen of the oestrous mare by the operator's sterile gloved arm in the vagina, as described by Bracher and Allen (1992). Under visual control the endoscope was directed along the uterine horn ipsilateral to the ovary containing a preovulatory follicle of $35 \mathrm{~mm}$ in diameter. When the tip of the endoscope came to within $3-5 \mathrm{~cm}$ of the papilla of the uterotubal junction, first the outer cannula and then the inner GIFT catheter containing the sperm suspension were extruded from the working channel until the tip of the GIFT catheter touched the papilla. The plunger of the syringe was then depressed to deposit the small volume of inseminate in the form of a froth which clung to the surface of the papilla (Fig. 1a,b). No attempt was made to pass the catheter into the external os of the papilla which, although clearly visible in most instances, was too small and convoluted to permit easy entry of the catheter into the oviductal lumen. The endoscope was steadily withdrawn from the uterus while simultaneously evacuating the filtered air that had previously been introduced to facilitate passage of the instrument through the lumen.

Mares with a preovulatory follicle were selected randomly to represent each insemination dose on each experimental day. The mares were inseminated in order of increasing insemination dose on any particular day and the GIFT catheter was discarded after inseminating six mares to prevent contamination of the low insemination doses with residual spermatozoa from a higher dose. An ovulation inducing dose of either $3000 \mathrm{iu} \mathrm{hCG} \mathrm{(Chorulon;} \mathrm{Intervet}$ Laboratories, Cambridge) or $2.1 \mathrm{mg}$ of the $\mathrm{GnRH}$ analogue deslorelin, administered as a slow-release subcutaneous implant (Ovuplant; Peptide Technology Ltd, Sydney), was given to each mare, either at the time of insemination or up to a maximum of $8 \mathrm{~h}$ before insemination.

\section{Fertility assessment}

Mares were allocated into one of six groups, each of which comprised a mixture of Thoroughbred and pony mares aged 2-18 years. Seven of the mares in group 3 (inseminated with $1 \times 10^{6}$ spermatozoa) included maiden ponies destined for slaughter during annual culling of the experimental herd. The mares in groups 1, 2, 3, 4, 5 and $6(n=8,10,25,10,11$ and 10 , respectively) were each inseminated once with, respectively, 10.0, 5.0, 1.0, 0.5, 0.1 and $0.001 \times 10^{6}$ Percolltreated motile spermatozoa. Their ovaries were examined by transrectal ultrasound scanning once a day after insemination to determine ovulation, which was confirmed by measuring an increase in progesterone concentrations in jugular vein serum samples taken once a day using the amplified enzyme linked immunoassay (AELIA) described by Allen and Sanderson (1987). The mares were re-scanned for determination of pregnancy between days 14 and 16 after ovulation, followed by a further ultrasound examination performed between days 22 and 30 to confirm the presence of a viable embryo in the conceptus. Subsequently, the pregnancy was terminated by giving an i.m. injection of 250-375 $\mu \mathrm{g}$ cloprostenol to induce luteolysis.

Seven of the mares in group 3, inseminated with $1 \times 10^{6}$ spermatozoa, were shot 2 days after ovulation and their reproductive tracts were removed immediately. The oviduct ipsilateral to the ovulated follicle was dissected from the mesosalpinx and its lumen was flushed with warmed $\left(35-37^{\circ} \mathrm{C}\right)$ PBS. Oocytes and embryos recovered from the flushed fluid were examined first under a dissecting microscope and then as a whole wet mount by phasecontrast microscopy to assess their stage of development and 

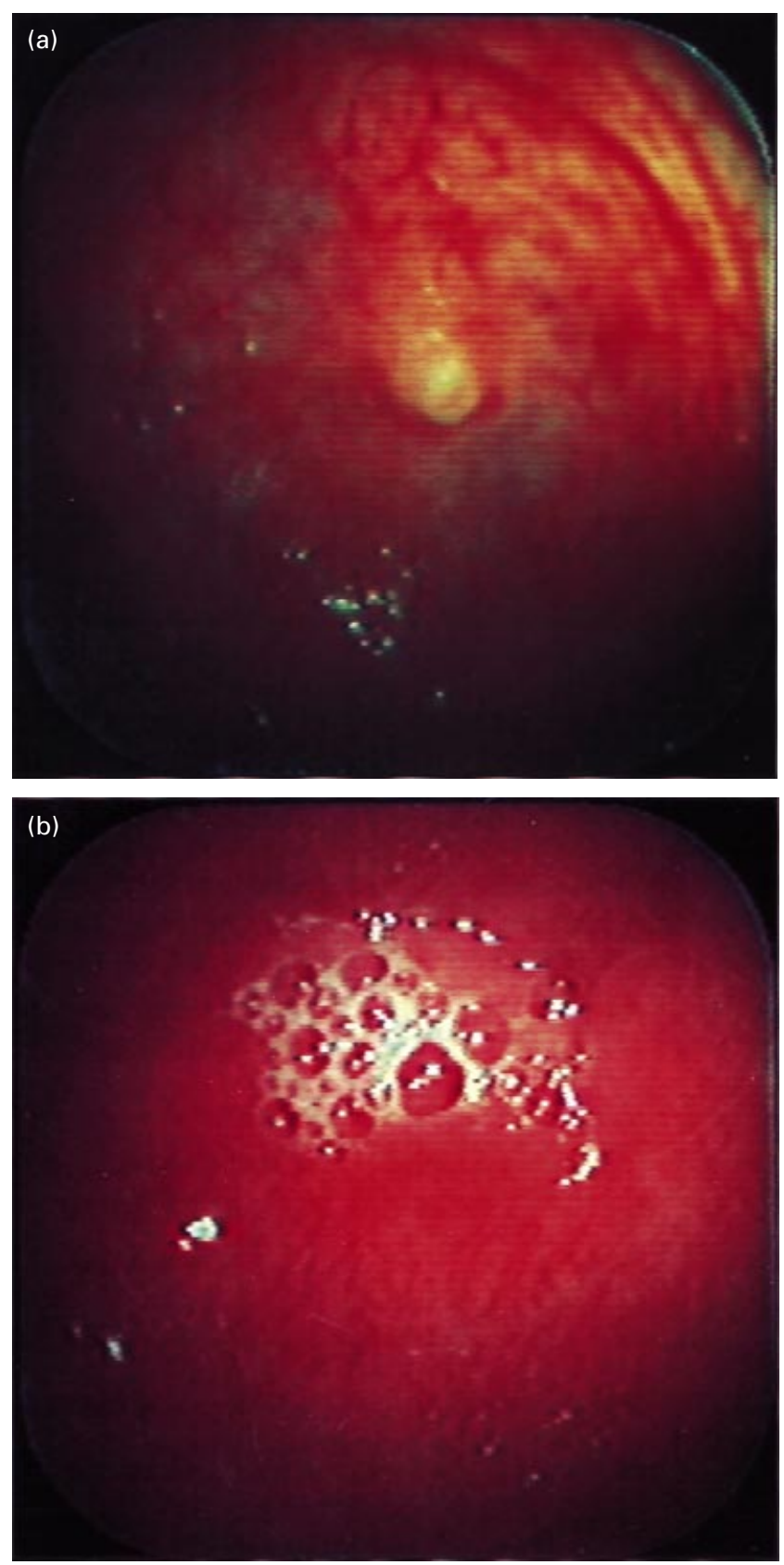

Fig. 1. (a) Uterine papilla of the equine uterotubal junction. (b) Processed semen deposited onto the papilla of the equine uterotubal junction. Note the presence of bubbles which help the inseminate adhere to the uterine surface of the papilla.

count the blastomeres. They were stained with $1 \%(\mathrm{w} / \mathrm{v})$ aceto-orcein to assess nuclear development.

Difficulty in traversing the excessively oedematous endometrium made it impossible to locate the uterotubal papilla in three mares. Accordingly, the inseminate was simply deposited in the lumen of the anterior portion of the ipsilateral uterine horn. These three mares, and a fourth mare that failed to ovulate within 4 days after uterotubal insemination, were excluded from the final analysis.

\section{Statistical analysis}

Chi-squared tests were performed to analyse any differences between treatment groups in the proportions of mares that conceived and to assess the influence of factors such as sperm motility, volume of the inseminate and the time from insemination to ovulation.

\section{Results}

Uniformly high conception rates of 60,75 and $64 \%$ were achieved in the mares in groups 1, 2 and 3, inseminated with 10, 5 and $1 \times 10^{6}$ spermatozoa, respectively (Fig. 1). Embryos were recovered from the oviductal flushings of six of the seven mares that were killed 2-3 days after ovulation. Two or three cleavage divisions had occurred to give four- to eightcell embryos at 2-3 days after ovulation (Table 1). A layer of cumulus cells remained associated with several of the embryos but none of them showed any accessory spermatozoa on the surface of the zona pellucida at the time of collection. Degenerate oocytes from previous oestrous cycles were observed in several instances, but no systematic search was made for unfertilized oocytes after recovery of the embryo. Conception rates in groups 4, 5 and 6, inseminated with $0.5,0.1$ or $0.001 \times 10^{6}$ spermatozoa, respectively, were markedly decreased $(29,22$ and 10\%, respectively) (Fig. 2).

There was no difference in the conception rate between the two stallions used (stallion 1, 19/44; 43\% versus stallion 2,

Table 1. Developmental stages of oocytes recovered 2-3 days after ovulation in mares inseminated using a hysteroscopic procedure

\begin{tabular}{ccl}
\hline $\begin{array}{l}\text { Interval from ovulation to } \\
\text { flushing the oviduct (days) }\end{array}$ & $\begin{array}{c}\text { Number of } \\
\text { mares }\end{array}$ & \multicolumn{1}{c}{$\begin{array}{c}\text { Stage of } \\
\text { development }\end{array}$} \\
\hline 2 & 1 & Unfertilized oocyte \\
2 & 3 & Four to five cells \\
2 & 2 & Eight cells \\
3 & 1 & Eight cells \\
\hline
\end{tabular}

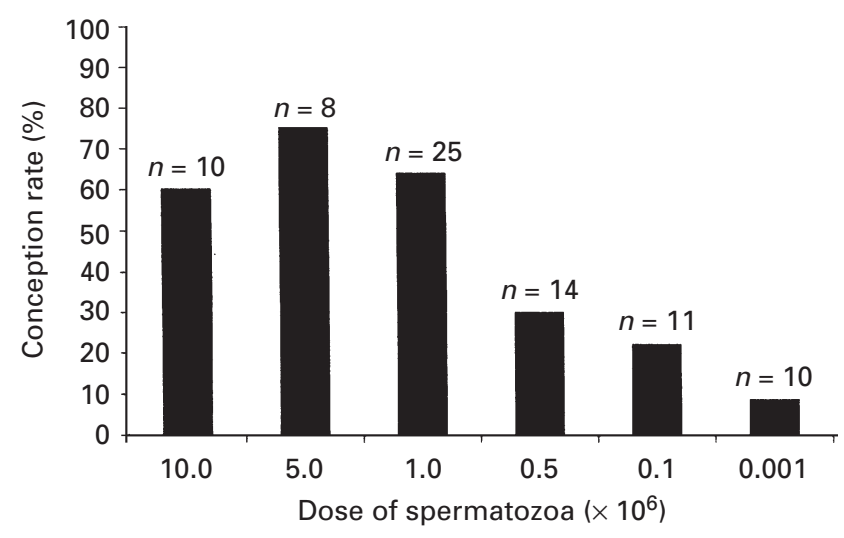

Fig. 2. Conception rates achieved by hysteroscopic insemination of low doses of spermatozoa directly onto the uterotubal papilla in mares ( $n=$ number of mares in each treatment group). 
$16 / 34 ; 47 \%)$. Centrifuging the diluted ejaculate through the Percoll gradient produced a definite increase in the proportion of total progressively motile spermatozoa (mean $\pm \mathrm{SD}$ ) from $58.3 \pm 0.07 \%$ in the raw sample to $70.0 \pm 0.07 \%$ in the final inseminate for both stallions over the 27 days of the experiment. The final volume of the inseminate used in each group varied between 30 and $150 \mu \mathrm{l}$ to provide the calculated insemination dose without exceeding a twofold increase in the concentration of spermatozoa among the mares in groups $1-5$. However, in the group 6 mares, the volume of the inseminate was maintained at $60-70 \mu \mathrm{l}$ to provide a manageable volume for aspiration into the GIFT catheter. Chi-squared analysis of the data revealed that the insemination volume did not significantly influence the conception rates.

The mean \pm SEM diameter of the preovulatory follicle at the time of insemination was $39.1 \pm 3.8 \mathrm{~mm}$. Ovulation was detected on day 2 after treatment with the ovulation induction agent in $79.1 \%$ of the mares, but this interval ranged from 1 to 4 days in all mares included in the study. There was no detectable influence of the ovulation inducing agent used, hCG or GnRH, on either the time from treatment to ovulation or the proportion of mares in each treatment group that conceived.

\section{Discussion}

The most important finding in this experiment is that hysteroscopic-guided insemination of very small numbers of Percoll-treated spermatozoa onto the uterotubal junction before ovulation in mares can result in a high incidence of fertilization and embryonic development; apparently normal pregnancies were established from 35 inseminations $(45 \%)$ by this approach. The marked decrease in the conception rate after insemination with $0.5 \times 10^{6}$ spermatozoa, compared with those achieved with $1.0 \times 10^{6}$ spermatozoa indicates that $1.0 \times 10^{6}$ spermatozoa are required for uterotubal insemination to give an acceptable conception rate. The observation that one mare conceived after insemination of only $1 \times 10^{3}$ spermatozoa at the uterotubal junction demonstrates that the sperm reservoir in the oviduct before fertilization may be extremely small. This successful conception also reflects the possible role of the crypts of the uterotubal junction in the storage of spermatozoa before their entry into the oviduct.

A conception rate of $64 \%$ was achieved from 25 inseminations of $1.0 \times 10^{6}$ Percoll-treated motile spermatozoa, which is considerably higher than the conception rates of $33 \%$ from $3.8 \times 10^{6}$ spermatozoa and $22 \%$ from $1.0 \times 10^{6}$ spermatozoa reported by Vazquez et al. (1998) and Manning et al. (1998), respectively. Both groups used a hysteroscopic deposition technique onto or into, respectively, the ipsilateral uterotubal papilla, similar to that used in the present study. The higher pregnancy rate in the present study compared with those of the other two groups attempting a similar low-dose hysteroscopic insemination procedure, highlights the potential value of the Percoll gradient centrifugation step in removing seminal plasma and skim-milk diluent to concentrate the proportion of motile spermatozoa in the minimized inseminate. This method may simulate more effectively the sperm selection gradient that would occur in vivo after natural mating or conventional uterine body insemination. Furthermore, the small diameter of the lumen of the uterotubal papilla, as described and measured by Manning et al. (1998), made passage of the catheter into the lumen very difficult in both the present study and that of Vazquez et al. (1998). Therefore, it is possible that entry into the lumen of the uterotubal papilla performed in the study by Manning et al. (1998) may have induced some degree of inflammation that reduced the success of the technique. It is also speculated that the creation of froth during deposition of the inseminate facilitates the adherence of the spermatozoa to the surface of the uterotubal papilla.

During the corresponding period of the 1998 breeding season, the two stallions used in this experiment had together achieved a per service conception rate of $86 \%$ over 42 oestrous cycles when artificially inseminating $500 \times 10^{6}$ spermatozoa into the posterior part of the uterine body. The high conception rate maintained with a 500-fold reduction in the number of spermatozoa in the present study indicates the efficiency and potential value of the hysteroscopic insemination method, especially when the availability of viable spermatozoa is restricted. This technique could be proposed as a means of making better use of semen from subfertile stallions, to overcome the limitations of oligospermy or improve the fertility of poorly cryopreserved semen samples. However, its greatest attraction lies in overcoming the considerable restriction on the number of viable spermatozoa produced by FACS separation of $X$ and $Y$ spermatozoa. An insemination dose as low as $1 \times 10^{6}$ spermatozoa is well within the capacity of modern FACS machines dedicated to separating $\mathrm{X}$ and $\mathrm{Y}$ spermatozoa (Johnson et al., 1989, 1994, 1998).

In the hysteroscopic approach used in the present study it was the number of spermatozoa in the inseminate, and not the volume, that was important in determining conception. In contrast to the results of the present study in which small volumes of inseminate were used $(0.03-0.15 \mathrm{ml})$, Manning et al. (1998) found an effect of the volume of inseminate when relatively larger volumes $(0.16-12.0 \mathrm{ml})$ were used. These technical aspects will become relevant in the development of techniques used to exploit the small number of spermatozoa available after FACS sorting of spermatozoa into populations bearing $X$ and $Y$ chromosomes. Secondly, it is valuable to visualize the uterotubal papilla at insemination, so that a very small volume of frothy inseminate can be inseminated directly onto its surface. It may be significant that conception was not achieved in the three mares in which the inseminate could only be deposited towards the anterior tip of the ipsilateral uterine horn due to the inability to locate and positively identify the uterotubal junction.

Although questions remain concerning the transport and storage of spermatozoa in the reproductive tract of mares, the findings of the present study indicate that deposition of spermatozoa onto the uterotubal papilla facilitates entry of viable spermatozoa into the isthmus of the Fallopian tube, thus avoiding dispersal and the extensive phagocytosis that would otherwise occur within the uterine lumen. Scott $e t$ al. 
(in press) found spermatozoa on the uterine side of the uterotubal junction in various glands and crypts in artificially inseminated mares, and suggested that the uterine papillae of the junction may be an important site of preovulatory sperm storage. Shortly after mating to a competent stallion, the whole of the interior of the uterus, including the regions around the uterotubal junctions, are bathed in the products of ejaculation (Mann et al., 1956). Thus, the observation of intact spermatozoa on the uterine side of the uterotubal junction within $4 \mathrm{~h}$ of insemination may only indicate a successful mating or insemination. A more interesting question is whether the variations in sperm density in the 'fractions' of the ejaculate might facilitate passage of a sperm-rich portion towards the uterotubal junction (see Du Mesnil du Buisson and Dauzier, 1955; Parker et al., 1975). If such an establishment of a sperm-rich fraction at the uterotubal junction after natural service does occur, it is reasonable to suspect that this may have been mimicked by the deposition of spermatozoa on the uterotubal junction in the present study, that is, deposition of a million or so highly motile spermatozoa on the uterotubal junction may be similar to an aliquot of the ejaculate arriving there naturally during service. Indeed, despite an expected depletion of the sperm reservoir over time, the results of the present study have demonstrated that $1-10 \times 10^{6}$ spermatozoa deposited on the uterotubal papilla provided an adequate number of spermatozoa to maintain a fertilizing sperm reservoir over periods of 1-4 days. The marked decrease in conception rate that occurred when the insemination dose was reduced below $1 \times 10^{6}$ motile spermatozoa indicates that this value may be near the cut-off point in the number of spermatozoa required to populate the uterotubal junction and maintain a functional sperm reservoir that would guarantee subsequent high levels of fertilization.

Despite the presence of tissue folds, simple glands and deep crypts at the uterotubal junction, spermatozoa remaining on the uterine side of this papilla would be vulnerable to the post-coital infiltration of polymorphonuclear leucocytes characteristic of equids, unless there is a special protective influence of local secretions against phagocytosis. However, viable spermatozoa probably negotiate the uterotubal junction largely by their own progressive motility, to escape from the bulk of the seminal plasma, uterine bacteria and polymorphs and to form a functional sperm reservoir in the caudal isthmus of the Fallopian tube. Such a preovulatory reservoir has been widely documented in laboratory rodents such as mice (Suarez, 1987) and golden hamsters (Smith and Yanagamachi, 1989), in rabbits (Overstreet and Cooper, 1975), and in farm animals like sheep (Hunter and Nichol, 1983), pigs (Hunter, 1984) and cows (Hunter and Wilmut, 1984). Although conclusive evidence of a sperm reservoir in the caudal isthmus of mares was not found in the study by Boyle et al. (1987), subsequent reports have strongly supported the contention (Thomas et al., 1994a,b; Dobrinski et al., 1996). Arguments in favour of this proposal include: (i) functional sperm reservoirs are not usually located at or within the site of ejaculation (that is, the uterus in mares), but are generally in a subsequent compartment of the tract (see Hafez and Thibault, 1973); (ii) during the relatively long preovulatory interval in mares, a population of spermatozoa with fertilizing capabilities needs to be sequestered away from the stimulating influences of both uterine and ampullary luminal fluids; (iii) sequestration is seemingly achieved within a specific glycoprotein secretion that accumulates in the caudal isthmus of the Fallopian tube (see Rodriguez-Martinez et al., 1998); and (iv) sperm arrest during the preovulatory interval in the functional sperm reservoir is facilitated by adhesion of the spermatozoon to the endosalpinx. Such binding between the apical portion of the sperm head and specific organelles in the epithelial cells has already been demonstrated in stallion spermatozoa in in vitro cultures of endosalpingeal cells (Thomas et al., 1994a; Dobrinski et al., 1996). Taken together, these various arguments indicate the likelihood of a functional sperm reservoir in the caudal isthmus of the equine Fallopian tube. The success of the hysteroscopic technique may lie in the fact that some of the uterine defence mechanisms are bypassed by deposition of spermatozoa directly onto the crypts of the uterotubal junction. Decreasing the number of spermatozoa has revealed that there is a minimal number required at the uterotubal junction for the formation of a functional sperm reservoir.

Hysteroscopic insemination at the uterotubal junction is an attractive and practical technique to improve fertility in mares and should have a considerable future. It is a straightforward manipulation to perform in the majority of mares and its requirement for small numbers of spermatozoa offers potential use and refinement of many modern breeding technologies, including exploitation of poorly cryopreserved semen samples, oligospermic ejaculates and the application of accurate sex-selection at fertilization in Sport horses.

This study was kindly financed by The Moller Trust, The Horserace Betting Levy Board and The Thoroughbred Breeders' Association. The authors are grateful to Susanna Mathias for expert assistance with videoendoscopy.

\section{References}

Allen WR and Sanderson MW (1987) The value of a rapid progesterone assay (AELIA) in equine stud veterinary medicine and management. In Proceedings of the 9th Bain-Fallon Memorial Lectures pp 76-82 Ed. P Huntington. AEVA, Sydney

Boyle MS, Cran DG, Allen WR and Hunter RHF (1987) Distribution of spermatozoa in the mare's oviduct Journal of Reproduction and Fertility Supplement 35 79-86

Bracher V and Allen WR (1992) Videoendoscopic examination of the mare's uterus I. Findings in normal fertile mares Equine Veterinary Journal 24 274-278

Day FT (1942) Survival of spermatozoa in the genital tract of the mare Journal of Agricultural Science 32 108-111

Dobrinski I, Thomas PGA and Ball BA (1996) The oviductal sperm reservoir in the horse: functional aspects Proceedings of the Annual Meeting of the Society for Theriogenology 265-270

Du Mesnil du Buisson F and Dauzier L (1955) La remontée des spermatozoides du verrat dans le tractus de la truie en oestrus Comptes Rendus Séances Societé de Biologie 149 76-79

Grøndahl C, Host T, Brück I, Viuff D, Bézard J, Fair T, Greve T and Hyttel P (1996) In vitro production of equine embryos Biology of Reproduction, Monograph Series I 299-307

Hafez ESE and Thibault C (1973) Sperm Transport, Survival and Fertilising Ability INSERM Colloquium Publication, Paris 
Hunter RHF (1984) Preovulatory arrest and peri-ovulatory redistribution of competent spermatozoa in the isthmus of the pig oviduct Journal of Reproduction and Fertility 72 203-211

Hunter RHF and Nichol R (1983) Transport of spermatozoa in the sheep oviduct: preovulatory sequestering of cells in the caudal isthmus Journal of Experimental Zoology 228 121-128

Hunter RHF and Wilmut I (1984) Sperm transport in the cow: peri-ovulatory redistribution of viable cells within the oviduct Reproduction, Nutrition and Development 24 597-608

Johnson LA, Flook JP and Hawk HW (1989) Sex preselection in rabbits. Live births from $\mathrm{X}$ and $\mathrm{Y}$ sperm separated by DNA and cell sorting Biology of Reproduction 41 199-203

Johnson LA, Cran DG and Polge C (1994) Recent advances in sex preselection of cattle: flow cytometric sorting of X- and Y-chromosome bearing sperm based on DNA to produce progeny Theriogenology 41 51-56

Johnson LA, Welch GR, Rens W and Dobrinsky JR (1998) Enhanced flow cytometric sorting of mammalian $X$ and $Y$ sperm: high speed sorting and orienting nozzle for artificial insemination Theriogenology 49361

Kenney RM, Bergman RV, Cooper WL and Morse GW (1975) Minimal contamination techniques for breeding mares: technique and preliminary findings Proceedings of the American Association of Equine Practitioners 327-335

Lefebvre R, De Mott RP, Suarez SS and Samper JC (1995) Specific inhibition of equine sperm binding to oviductal epithelium Biology of Reproduction, Monograph Series I 689-696

Mann T, Polge EJC and Rowson LEA (1956) Participation of seminal plasma during the passage of spermatozoa in the female reproductive tract of the pig and horse Journal of Endocrinology 13 133-140

Manning ST, Bowman PA, Fraser LM and Card CE (1998) Development of hysteroscopic insemination of the uterine tube in the mare Proceedings of the Annual Meeting of the Society for Theriogenology 84-85 (Abstract)

Navarro MC, Valencia J, Vasquez J, Cózar E and Villaneuva C (1998) Crude mare follicular fluid exerts chemotactic effects on stallion spermatozoa Reproduction in Domestic Animals 33 321-324
Overstreet JW and Cooper GW (1975) Reduced sperm motility in the isthmus of the rabbit oviduct Nature 258 718-719

Parker WG, Sullivan JJ and First NL (1975) Sperm transport and distribution in the mare Journal of Reproduction and Fertility Supplement 23 63-66

Pickett BW and Voss JL (1975) The effect of semen extenders and sperm number on mare fertility Journal of Reproduction and Fertility Supplement 23 95-98

Rodríguez-Martínez H, Larsson B, Pertoft H and Kjellén L (1998) GAGs and spermatozoon competence in vivo and in vitro. In Gametes: Development and Function Serono Symposia 239-272

Scott MA, Liu IKM, Overstreet JW and Enders AC The structural morphology and epithelial association of spermatozoa at the utero-tubal junction: a descriptive study of equine spermatozoa in situ using scanning electron microscopy Journal of Reproduction and Fertility Supplement (in press)

Smith TT and Yanagimachi R (1989) Capacitation status of hamster spermatozoa in the oviduct at various times after mating Journal of Reproduction and Fertility 86 255-261

Suarez SS (1987) Sperm transport and motility in the mouse oviduct: observations in situ. Biology of Reproduction 36 203-210

Thomas PGA, Ball BA and Brinsko SP (1994a) Interaction of equine spermatozoa with oviduct epithelial cell explants is affected by estrous cycle and anatomic origin of explant Biology of Reproduction 51 222-228

Thomas PGA, Ball BA, Miller PG, Brinsko SP and Southwood L (1994b) A subpopulation of morphologically normal, motile spermotozoa attach to equine oviductal epithelial cell monolayers Biology of Reproduction 51 303-309

Vazquez JJ, Medina V, Liu IK, Ball BA and Scott MA (1998) Nonsurgical utero-tubal insemination in the mare Proceedings of the Annual Meeting of the Society for Theriogenology 82-83 (Abstract)

Zhang JJ, Muzs LZ and Boyle MS (1991) Variations in structural and functional changes of stallion spermatozoa in response to calcium ionophore A23187 Journal of Reproduction and Fertility Supplement 44 199-205 